Numerical Simulation of Wake Vortices Measured During the Idaho Falls and Memphis Field Programs

\author{
Fred H. Proctor \\ NASA Langley Research Center \\ Flight Dynamics \& Control Division \\ Hampton, VA 23681-0001
}

14th AIAA Applied Aerodynamic Conference

17-20 June 1996, New Orleans, Louisiana

AIAA Paper No. 96-2496 


\title{
NUMERICAL SIMULATION OF WAKE VORTICES MEASURED DURING THE IDAHO FALLS AND MEMPHIS FIELD PROGRAMS
}

\author{
Fred H. Proctor \\ NASA Langley Research Center \\ Flight Dynamics \& Control Division \\ Hampton, VA 23681-0001
}

\begin{abstract}
A numerical large-eddy simulation model is under modification and testing for application to aircraft wake vortices. The model, having a meteorological framework, permits the interaction of wake vortices with environments characterized by crosswind shear, stratification, and humidity. As part of the validation process, model results are compared with measured field data from the 1990 Idaho Falls and the 1994-1995 Memphis field experiments. Cases are selected that represent different aircraft and a cross section of meteorological environments. Also included is one case with wake vortex generation in ground effect. The model simulations are initialized with the appropriate meteorological conditions and a post roll-up vortex system. No ambient turbulence is assumed in our initial set of experiments, although turbulence can be self generated by the interaction of the model wakes with the ground and environment.
\end{abstract}

\section{Introduction}

In response to a continuing trend for increased air travel that has led to more frequent delays and increased costs to air carriers and the traveling public, NASA through its Terminal Area Productivity (TAP) program is developing systems that will increase efficiency, yet ensure safety to the traveling public. A major element to this program is the development of an automated system called the Aircraft Vortex Spacing System (AVOSS) -- which will determine safe operating spacings between arriving/departing aircraft as based on the observed/predicted weather state. ${ }^{1}$ At the core of AVOSS will be a predictor algorithm that relates the transport and decay of aircraft wake vortices to the present and future weather state. The presences of strong crosswinds and vigorous environmental turbulence, for example, may lessen the threat of a dangerous wake vortex encounter, and thus allow a tightening up of wake vortex separation standards now in effect during instrument meteorological conditions.

NASA-Langley theoretical modelling efforts are expected to play a major role in the development of these algorithms. A numerical large-eddy simulation model called the Terminal Area Simulation System ${ }^{2}$ (TASS) has been modified for application to aircraft wake vortex simulations. The TASS model, which is described in section 2, is believed to have an advantage over other wake vortex models $3,4,5,6,7,8$ in that it has a meteorological reference frame, compressible nonBoussinesq equation set, subgrid turbulence closure, a formulation for ground-friction, realistic boundary conditions, an option for either two or three spatial dimensions, and accurate -- yet computationally efficient -- numerical approximations. In spite of the model's sophistication, it has relatively fast execution times, which is an important feature when taking on the ambitious task of simulating three-dimensional, timedependent aircraft wakes. The TASS model is capable of simulating post roll-up wake vortices in both two and three dimensions, for a wide range of atmospheric conditions that include: vertical wind shear, stratification, atmospheric boundary layer turbulence, fog, and precipitation. Initial emphasis is being placed on validation. Once this has been accomplished with sufficient confidence, then TASS model output will be used to develop parametric relationships for vortex transport and decay as related to different aircraft types (e.g., B-767, DC-10, etc.) and meteorological conditions (windshear, stratification, ambient turbulence, humidity and precipitation). The model can also provide high spatial resolution fields of wind, pressure, temperature, and humidity, for analyzing and understand the structure of wake vortices. The generated high-resolution fields

Copyright (C) 1996 by the American Institute of Aeronautics, Inc. No copyright is asserted in the United States under Title 17, U.S. Code. The U.S. Government has a royalty-free license to exercise all rights under the copyright claimed herin for government purposes. All other rights are reserved by the copyright owner. 
will be valuable in the characterization and quantification of wakes generated in various meteorological scenarios, as well as for providing realistic data sets for wake vortex sensor development.

The purpose of this paper is to give an overview of the TASS model and to present results of its application to wake vortex research. Two-dimensional simulations of cases from the 1990 FAA Idaho Falls and from the Memphis 1994 and 1995 NASA/MITLincoln-Laboratory wake-vortex field deployments are presented. Results from the computational simulations, including comparisons with measurements, are presented for the Idaho Falls cases in section 4 and for the Memphis cases in section 5. Details of the TASS model are described in the next section and the initialization procedure is reported in section 3 .

\section{Model Description}

The TASS model is a multi-dimensional, largeeddy code that has been used to study a variety of meteorological phenomenon including convective local storms, ${ }^{9}$ microburst/windshear, ${ }^{10,11,12,13}$ hailstorms, ${ }^{14}$ tornadic thunderstorms, ${ }^{15}$ nuclear cloud rise, ${ }^{16}$ and atmospheric boundary layer turbulence. ${ }^{17,18}$ The TASS model has been validated with observed data for a range of micro- and cloud-scale phenomena, and was highly successful in the completed NASA-FAA windshear program. Recent modifications to the initial conditions allow for its application to aircraft wake vortex phenomenon. Thus the model is not merely a "wake vortex model," but can be generically applied to a diversity of phenomena. The model includes parameterizations for ground stresses that are a function of surface roughness, allowing for "in-ground effect" wake simulations with realistic ground interactions.

The TASS model consists of 12 prognostic equations: three equations for momentum, one equation each for pressure deviation and potential temperature, six coupled equations for continuity of water substance (water vapor, cloud droplet water, cloud ice crystals, rain, snow and hail) and a prognostic equation for a massless tracer. The non-Boussinesq formulation used in TASS was initially developed to study tornadoes with application to similar intense vortices. ${ }^{19}$ This formulation was subsequently extended to a compressible time-split formulation, and parameterizations for numerous microphysical interactions were included as an option. ${ }^{2}$ Salient characteristics of the TASS
Table 1. Salient Characteristics of TASS 6.x

Primitive equation / non-Boussinesq equation set Time-dependent, nonhydrostatic, compressible

Meteorological framework with option for either three-dimensional or two-dimensional simulations

Liquid and ice phase microphysics - can simulate growth processes for cloud droplets, cloud ice crystals, rain, snow and hail. Accomplished with large set of microphysical-parameterization models

Inverse-exponential size distributions for precipitating hydrometeors

Large Eddy Simulation model with 1st-order subgrid scale turbulence closure - scales of turbulence larger than grid volume are resolved in the simulation

Ground stress based on Monin-Obukhov Similarity theory

Choice of lateral boundaries: may be either open, mirror, or periodic -- open condition utilizes massconservative, nonreflective radiation boundary scheme

Option for nonstationary domain -- movable, storm/vortex centering mesh

Explicitnumerical schemes, quadratic conservative, time-split compressible-- accurate and highly efficient, almost no numerical diffusion

Arakawa C-grid staggered mesh, and vertical coordinate stretching allowed

Filter and sponge applied to top four rows so as to diminish gravity wave reflection at top boundary

Ambient atmospheric conditions initialized with vertical profile of pressure or altitude, temperature, dew point, and wind velocity

Model applicable to meso- $\gamma$ and micro scale atmospheric phenomenon. Initialization modules for simulation of convective storms, microbursts, atmospheric boundary layers, and aircraft wake vortices

model are listed in table 1. 
The TASS equation set in standard tensor notation is as follows:

Momentum:

$$
\begin{gathered}
\frac{\partial u_{i}}{\partial t}+\frac{H}{\rho_{o}} \frac{\partial p}{\partial x_{i}}=-\frac{\partial u_{i} u_{j}}{\partial x_{j}}+u_{i} \frac{\partial u_{j}}{\partial x_{j}}+g(H-1) \delta_{i 3} \\
-2 \Omega_{j}\left(u_{k}-u_{o_{k}}\right) \varepsilon_{i j k}+\frac{1}{\rho_{o}} \frac{\partial \tau_{i j}}{\partial x_{j}}
\end{gathered}
$$

Buoyancy Term:

$$
H=\left[\frac{\theta}{\theta_{o}}-\frac{p C_{v}}{P_{o} C_{p}}\right]\left[1+0.61\left(Q_{v}-Q_{v o}\right)-Q_{T}\right]
$$

Pressure Deviation:

$$
\frac{\partial p}{\partial t}+\frac{C_{p} P}{C_{V}} \frac{\partial u_{j}}{\partial x_{j}}=\rho_{o} g u_{j} \delta_{j 3}+\frac{C_{p}}{C_{v}} \frac{P}{\theta} \frac{d \theta}{d t}
$$

Thermodynamic Equation (Potential Temperature):

$$
\begin{aligned}
\frac{\partial \theta}{\partial t}=- & \frac{1}{\rho_{o}} \frac{\partial \theta \rho_{o} u_{j}}{\partial x_{j}}+\frac{\theta}{\rho_{o}} \frac{\partial \rho_{o} u_{j}}{\partial x_{j}}+\frac{1}{\rho_{o}} \frac{\partial S_{j}(\theta)}{\partial x_{j}} \\
& +\frac{\theta}{T C_{p}}\left[L_{v} s_{v}+L_{f} s_{f}+L_{s} s_{s}\right]
\end{aligned}
$$

with the Potential Temperature being defined as:

$$
\theta=T\left(\frac{P_{o o}}{P}\right)^{\frac{R_{d}}{C_{p}}}
$$

In the above equations, $u_{i}$ is the tensor component of velocity, $t$ is time, $p$ is deviation from atmospheric pressure $P, T$ is atmospheric temperature, $\rho$ is the air density, $\Omega$ is the earth's angular velocity, $C_{p}$ and $C_{v}$ are the specific heats of air at constant pressure and volume, $g$ is the earth's gravitational acceleration, $R_{d}$ is the gas constant for dry air, $P_{o o}$ is a constant equivalent to 1000 millibars $\left(10^{5}\right.$ pascals) of pressure, $Q_{v}$ is the mixing ratio for water vapor, and $Q_{T}$ is the sum of the mixing ratios for liquid and ice water substance, $L_{v}$ is the latent heat for vaporization for water, $L_{f}$ is the latent heat for fusion for water, $L_{s}$ is the latent heat for sublimation for water, and $s_{v}, s_{f}$, and $s_{s}$ are the respective water substance source terms. Environmental state variables, e.g., $u_{o k}, Q_{v o}, \quad \rho_{o}$, and $\theta_{o}$, are defined from the initial input sounding and are functions of height only.
Conservation of Scalar Variables (e.g., water vapor, cloud droplet water, etc.)

$$
\frac{\partial Q}{\partial t}=-\frac{1}{\rho_{o}} \frac{\partial Q \rho_{o} u_{j}}{\partial x_{j}}+\frac{Q}{\rho_{o}} \frac{\partial \rho_{o} u_{j}}{\partial x_{j}}+\frac{1}{\rho_{o}} \frac{\partial S_{j}(Q)}{\partial x_{j}}+s_{Q}
$$

where $s_{Q}$ represents contribution from source terms. For precipitating variables (such as rain and snow), an additional vertical flux term is added to the above equation to account for fall out.

The dependent variables in TASS are treated as averages over the grid volumes -- giving rise to subgrid Reynold's stress and subgrid eddy transport terms. From first-order closure theory, the subgrid scalar covariances and subgrid stress are respectively:

$$
\begin{gathered}
S_{j}(Q)=\rho_{o} K_{H} \frac{\partial Q}{\partial x_{j}} \\
\tau_{i j}=\rho_{o} K_{M}\left[\frac{\partial u_{i}}{\partial x_{j}}+\frac{\partial u_{j}}{\partial x_{i}}-\frac{2 \partial u_{k}}{3 \partial x_{k}} \delta_{i j}\right]=\rho_{o} K_{M} D_{i j}
\end{gathered}
$$

A modified Smagorinsky first-order closure is used for the subgrid eddy viscosity:

$$
K_{M}=l_{s}^{2} \sqrt{\frac{\partial u_{i}}{\partial x_{j}}\left(\frac{\partial u_{i}}{\partial x_{j}}+\frac{\partial u_{j}}{\partial x_{i}}\right)-\frac{2}{3}\left(\frac{\partial u_{k}}{\partial x_{k}}\right)^{2}} \times \sqrt{1-R_{f}}
$$

The subgrid eddy viscosity is modified by stratification through the Flux Richardson Number, $R_{f}$, which is approximated from the Richardson number, $R i$, as:

$$
R_{f}=\operatorname{Min}\left[0.9998, \quad R i K_{H} / K_{M}\right]
$$

where the subgrid eddy viscosity for heat is specified as $K_{H}=3 K_{M}$. The Richardson number for moist, but unsaturated air is ${ }^{20}$

$$
R i=\frac{\frac{1}{\rho_{o} \theta} \frac{\partial P}{\partial x_{k}} \frac{\partial \theta\left(1+0.61 Q_{v}-Q_{T}\right)}{\partial x_{k}}}{D_{i j}^{2}}
$$

For saturated air (i.e. $100 \%$ relative humidity) the Richardson number is modified from above to account for the moist adiabatic ascent and descent of saturated air parcels. Therefore, $(1 / \theta) \partial \theta / \partial z$ is replaced with: 


$$
\frac{1}{\theta} \frac{\partial \theta}{\partial z}-\frac{g}{C_{p} T}\left[1-\frac{P+\frac{\varepsilon L_{v} e_{v}}{R_{d} T}}{P+\frac{\varepsilon L_{v}^{2} e_{v}}{C_{p} R_{v} T^{2}}}\right]
$$

where $R_{v}$ is the gas constant for water vapor, $\varepsilon=$ $R_{d} / R_{v}, z$ is the vertical coordinate, and $e_{v}$ is the vapor pressure for liquid water. The subgrid length scale, $l_{s}$, is determined from the grid volume and is matched to the appropriate length scale close to the ground where the flow is under-resolved. That is:

$$
l_{s}=\left[\begin{array}{cc}
\alpha \Delta & z \geq \alpha \Delta / k \\
\frac{\alpha \Delta\left[1+(\alpha \Delta / k z)^{m-1}\right]}{1+(\alpha \Delta / k z)^{m}} & \alpha \Delta / k>z>\Delta z / 2 \\
k z & z \leq \Delta z / 2
\end{array}\right.
$$

where $\mathrm{k}$ is von Karman's constant, and where $\mathrm{m}$ and $\alpha$ are invariant constants with values defined as $m=2.5$ and $\alpha=0.155$. The filter width is

$$
\Delta=\left[\begin{array}{lll}
2 \Delta x & 2 \Delta y & 2 \Delta z
\end{array}\right]^{1 / 3}
$$

where $\Delta x, \Delta y$, and $\Delta z$ are the numerical grid sizes in the respective $x, y, z$ direction.

The ground boundary is impermeable (except to precipitation) with nonslip velocity specifications. Surface stresses are computed locally from the nearground wind velocity, Richardson number, and surface roughness height.

An abbreviated discussion of the numerical approximations for the TASS equation set can be found in the Appendix.

\section{Initial Conditions}

\section{Grid/Domain Configuration}

For the simulations presented in this paper we have chosen the 2-D option for all simulations with $\Delta x$ $=\Delta y=\Delta z$, and have rotated the coordinate system such that $y$ is along the aircraft flight path and $x$ in the cross track direction; $z$ represents distance above the ground. The simulations are time integrated within the two-dimensional $x-z$ plane. In the cases presented here, a constant grid size of $3 / 4$ to 1 meter is used.

The computational domain size for each case simulation is governed by the size and height of the generating aircraft. In the event of strong crosswinds, wide domains are not needed since the numerical grid translates with the horizontal advection of the wake vortices. The top of the domain is chosen at least $50 \mathrm{~m}$ above the altitude of the generating aircraft. In the following cases, the horizontal domain size is between $150 \mathrm{~m}$ and $300 \mathrm{~m}$ wide and the vertical depth is between $100 \mathrm{~m}$ and $250 \mathrm{~m}$. The simulations use the open radiation boundary condition option at the two lateral boundaries, allowing minimal interference and distortion to the interior flow.

\section{Ambient Conditions}

Each case is initialized with its respective vertical distribution of observed temperature, dewpoint, and wind velocity, that represents the air mass surrounding the wake. Horizontal variations in the ambient conditions are not considered.

\section{Vortex Initialization}

As for the initial wake field, the two-dimensional simulations are initialized with a simple vortex system that is representative of the post roll-up, wake velocity field. The vortex system is initialized with the superposition of two counter-rotating vortices, with the velocity field for each vortex according to the BurnhamHallock model ${ }^{21}$ as:

$$
V(r)=\frac{\Gamma_{\infty} \quad r}{2 \pi r_{c}^{2}+r^{2}}
$$

where $V$ is the vortex tangential velocity, $r$ the radius, $r_{c}$ is the core radius (i.e. radius of peak tangential velocity), and $\Gamma_{\infty}$ the circulation at $r \gg r_{c}$. Appropriate vortex image conditions are applied to the initial wake field to ensure consistency and mass continuity at the model boundaries.

The parameters that govern the vortex initialization are: vortex separation, core size, height, and circulation. The height of the vortex system, $Z_{i}$, is determined from the observed height of the generating aircraft. The vortex core radius is assumed to be $5 \%$ of the generating aircraft's span. The remaining parameters are aircraft dependent and can be obtained from aerodynamic theory with the assumption of an ellipticallyloaded wing ${ }^{22}$ as:

$$
S=\frac{\pi}{4} B \quad \Gamma_{\infty}=\frac{4 M g}{\pi \rho V_{a} B}
$$


where $S$ is the vortex separation, $B$ is the span of the generating aircraft, $V_{a}$ is the true air speed, and $M$ is the mass of the generating aircraft.

This initialization procedure does not account for the aircraft configuration (i.e. flap settings, landing gear, inclined flight path); however, results from this procedure were found to give good comparisons with observations regardless of flight configuration.

\section{Turbulence Initialization}

All of the following cases assume that there is no preexisting ambient turbulence. However, turbulence (and the effects of turbulence) can develop in the simulations from the interaction of the wakes with either the ground or ambient environment. This assumption of no initial turbulence is acceptable for stably-stratified environments, since the affect of vortex generated turbulence likely overwhelms the affect due to any preexisting turbulence. Currently, an initialization for ambient turbulence is being developed, and future studies will evaluate its effect in both two- and threedimensional wake simulations.

\section{Execution Time}

The TASS code can be run on any modern computer or workstation that is equipped with a fortran compiler. However, the domain size and grid resolution will be limited by the host computer's memory and speed of execution. A typical two-dimensional wake vortex simulation with a 1-m grid resolution takes about 20 min of CPU time on a Cray C-90 supercomputer. For a fixed domain, the execution time is inversely proportional to the cube of the grid size. So a doubling (halving) of the resolution can increase (decrease) the execution time by a factor of eight.

\section{Results -- Idaho Falls}

The first set of TASS validation experiments are from the 1990 Idaho Falls, Idaho (IDF) field experiment. The principal aim of this FAA sponsored field study was to evaluate Boeing 757 and 767 aircraft wakes in a week-long series of tower fly-bys. An extensive data set was generated by a DOT/NOAA team containing wake vortex measurements and atmospheric data. $^{23,24}$ Vortex data was collected from a series of low-level flights in various flight configurations by a Laser Doppler Velocimeter (LDV), an array of Monostatic Acoustic Vortex Sensing System (MAVSS) sensors, and a $200 \mathrm{ft}(61 \mathrm{~m})$ instrumented tower.
Atmospheric data were measured by the tower and a tethersonde. The tests were conducted in September during mornings and extending into early afternoons. The prevalent atmospheric conditions were dry and stable with local drainage flows -- transitioning as the morning progressed -- to an unstable boundary layer that grew in depth due to solar heating.

From this data set, seven cases were chosen that represent a range of atmospheric conditions and aircraft types (table 2). Characterization of the meteorological conditions are represented by several parameters (also listed in table 2), which are: the vertical change in potential temperature $\Delta \theta / \Delta z$ (negative for unstable stratification, positive for stable), mean crosswind shear $\Delta U / \Delta z$, crosswind at flight level $U\left(Z_{I}\right)$, and a Bulk Richardson number based on the crosswind flow, i.e.,

$$
R i_{b}=\frac{g}{\theta} \frac{\Delta \theta / \Delta z}{(\Delta U / \Delta z)^{2}}
$$

where the mean gradients in the listed parameters are taken between $5 \mathrm{~m} \mathrm{AGL}$ and $15 \mathrm{~m}$ above the flight path.

Model validation experiments were conducted for each of the seven cases, with the input for ambient conditions constructed from the tower and tethersonde data. The tower provided excellent ambient wind and temperature information up to $61 \mathrm{~m}$. At higher elevation the tethersonde data was used, which unfortunately, was of lesser quality, being subject to errors from veryshort averaging times and bobbing of the balloon. Values for the initial vortex parameters (also included in table 2) were determined from aircraft dependent specifications and the reported weight, height, and speed of the generating aircraft. Comparison of the simulations with the measured data was generally very good with computed vortex trajectories having the best agreement. Good agreement was obtained independent of flight configuration and aircraft type. Comparison of model circulation values tended to upper-bound the observations, with the measurements indicating greater decay rates after one or two minutes. This was better than expected since the two-dimensional simulations do not allow vortex stretching and do not permit development of 3-dimensional decay processes such as vortex bursting and Crow instability. Three of the case simulations (listed in bold in table 2) are presented below. 


\section{B-757 Run-9}

This particular case was selected by the FAA as a standard against which all wake-vortex modelers could compare. ${ }^{25}$ The field observations indicated a strong and persistent upwind vortex from a B-757 fly-by at 0818 MST on 25 September. The B-757 was in a landing configuration and on a level flight path at $70 \mathrm{~m}$ AGL. The ambient atmosphere for the early morning flight was characterized by significant crosswinds (5.8 $\mathrm{m} / \mathrm{s}$ at flight level). The lapse rate for ambient temperature was stable, except below $20 \mathrm{~m}$ AGL due to the influence of the ground beginning to heat up. A strong crosswind shear was especially noted between 20 and $40 \mathrm{~m}$ AGL.

As shown in Fig. 1, comparisons between field data and TASS model results are extremely good. Both observations and model results show that the vortices initially descend due to the mutual interaction of their velocity fields. However, the vertical descent of the downstream (port) vortex is suppressed as it encounters moderate crosswind shear of opposite vorticity; and it eventually ascends upward with increasing lateral separation from the upstream (starboard) vortex. The upstream vortex descends to and remains near the ground, where it translates at relatively slower speeds due to the presence of weaker crosswinds. The model results show several minor bounces of the upstream vortex, resulting from the vortex interaction with the ground and production of secondary vortices.

The wind vector and potential temperature field at $90 \mathrm{sec}$ are shown in Figs. 2 and 3, with Fig. 2 also showing the observed positions of the wake vortices. Note that potentially warmer air is carried downward with the downwash between the vortices, and potentially cooler air is transported around the periphery of the vortices. [Potential temperature is conserved during dry processes, and thus acts as a fluid tracer.] Also evident in Fig. 3, is the presence of complex interactions between the ground and the upstream vortex, including the presence of an obvious secondary vortex.

\section{Average Circulation}

In order to characterize the strength of wake vortices, previous field investigators have defined a parameter called average circulation. ${ }^{21}$ According to reference 21, this parameter is preferable since it relates to the rolling moment of an encountering aircraft and it provides a more stable measurement than circulation. The average circulation is defined as

$$
\bar{\Gamma}^{a, b}=\frac{\int_{a}^{b} \Gamma_{r} d r}{\int_{a}^{b} d r}
$$

where the circulation is defined as

$$
\Gamma_{r}=\oint_{r} \boldsymbol{V} \cdot d \boldsymbol{l}
$$

or equivalently,

$$
\Gamma_{r}=\iint_{r} \zeta d A
$$

where $\mathrm{a}$ and $\mathrm{b}$ are the radii of the averaging interval, and $\zeta$ is the axial component of vorticity. Values for these parameters are easily determined from simulation data, but less so easily from observations.

Fig. 1 shows a comparison of the $10 \mathrm{~m}$ average circulation (i.e. the average circulation from $r=0$ to $r=10 \mathrm{~m}$ ) for TASS data, as well as that deduced from the tower, LDV and MAVSS measurements. The modeled $10 \mathrm{~m}$ average circulations of the two vortices are about equal in magnitude, and bound the estimated circulation from field measurements. The average circulation estimated from the MAVSS sensor seems too low, especially when compared with the LDV and tower data. The MAVSS estimates were probably low due to its poor resolution of the vortex core. ${ }^{26}$

Fig. 4 shows average circulation vs averaging radius at two different times from Run 9. The comparison between TASS and LDV data are quite good, even near the core region of the vortex.

Comparisons in Fig. 5 from TASS data show that the magnitude of the 5-15 m average circulation is closer to that of the initial circulation $\left[\Gamma\left(t=0, r \gg r_{c}\right)\right]$. Also apparent from the normalized curves in Fig. 5, the $10 \mathrm{~m}$ average circulation decays faster than the 5-15 m average circulation.

The purpose of the above discussion on circulation is not to advocate one parameter over the other, but to show that they can differ in magnitude and in rates of decay. When validating model simulations and defining separation standards based on vortex decay rates, one should not assume, for example, that the $10 \mathrm{~m}$ average circulation is (and decays) approximately the same as circulation. 


\section{IDF B-767, Runs 23 and 31}

Contrasting with Run 9 are two cases from B767 fly-bys that were flown in environments of weaker crosswind shear. In Run 23 the aircraft was in "takeoff" configuration within a stably-stratified environment. While in Run 31 the aircraft was in "landing configuration" within an environment of unstable stratification. Comparison between the TASS simulations and field data for these cases are shown in Figs. 6 and 7.

For run 23 (Fig. 6) there are no observations of the downstream vortex after $60 \mathrm{sec}$. In the model simulation after $80 \mathrm{sec}$, the downstream vortex diminished in size and intensity, as it was coalesced within the larger-scale circulation of the downstream vortex.

In run 31 (Fig. 7), the downstream vortex was no longer tracked after $40 \mathrm{sec}$, although the simulated downstream vortex remained intense.

In both of these events it is not known whether the downstream vortex suddenly decayed or was lost by the LDV sensor. In each of the events, both upstream and downstream vortices did encounter the tower, at positions and time intervals in agreement with the model simulation.

\section{Results -- Memphis}

The last set of TASS experiments are from the Memphis field experiments. The NASA-Langley sponsored field study was conducted by MIT Lincoln Laboratories, in November and December of 1994 and again in August 1995. ${ }^{27,28}$ The purpose of the study was to gather meteorological, wake vortex, and aircraft data at an operational airport, for use in validation of wake vortex models and for direct use in the development of the AVOSS prediction system. Aircraft wake vortex measurements were obtained with a 10.6 micron continuous wave laser with real time identification and tracking algorithms. ${ }^{29}$ Meteorological data included: a $150 \mathrm{ft}(46 \mathrm{~m})$ tower with sensors for wind velocity, temperature, and humidity; a radar profiler and acoustic sodar for measuring winds aloft; a radio acoustic sounding system (RASS) for providing temperature data; and frequent rawinsonde balloon launches, for obtaining the vertical profiles of wind velocity and temperature. Aircraft data, such as weight, type, and airspeed, as well as aircraft beacon data were collected. Lidar measurements were limited to arriving aircraft, with some of the 1995 cases set-up for measuring wakes generated in ground effect.

Simulation results and lidar data are shown in Figs. 8 and 9 for four of the cases. The selected cases, which are summarized in table 3 , represent a cross section of aircraft commonly encountered at international airports. One of the cases (\#1475) is for a MD-11 wake generated in ground effect.

The meteorological conditions for the selected cases are characterized as having light crosswinds with weak vertical shear. Since the shear was light, the vortex pairs descend to the ground with little increase in separation. The crosswinds for cases \#1254 and \#1475 are especially light, resulting in little lateral movement of the wakes (Fig. 9).

Comparisons between the modeled wake trajectories and lidar measurements are excellent, even for case \#1475, which is the MD-11 wake generated in ground effect. Both the TASS simulation and lidar measurement show the MD-11 wake slowly rising from its generation altitude of $17.5 \mathrm{~m}$ to an elevation of about $40 \mathrm{~m}$ (Fig. 8), with the starboard vortex remaining in the vicinity of the flight path (Fig. 9). Unfortunately, lidar measurements of the port vortex were unavailable for this case and two of the other Memphis cases.

\section{Summary}

Two-dimensional TASS wake vortex simulations were compared with field measurements for a range of meteorological conditions and aircraft types. Successful validation of two-dimensional TASS results were achieved with the initialization of the appropriate observed meteorological conditions and a post roll-up vortex system. Excellent agreement is obtained between TASS predicted trajectories and measurements. Good agreement was obtained whether the generating aircraft was in landing or take-off configuration. Results from the simulations indicate great sensitivity to meteorology, especially vertical wind shear. A vortex encountering a shear with opposite sense vorticity can be deflected upwards. Circulation values predicted by TASS are upper-bound for the observed values. The field data indicated a greater decay rate once the wake vortex was one to two minutes old. However, the future inclusion of initial turbulence fields and the extension to three 
dimensions should lead to a more realistic treatment of vortex decay.

Following successful validation, TASS parametric runs are to be used to quantify the effect of weather conditions on wake-vortex transport and decay, and provide data useful for development of predictor algorithms for aircraft spacing.

Table 2. Idaho Falls Validation Cases. Only those cases in bold are presented in this paper. $[\Delta \theta / \Delta z$ is the change in potential temperature with height, $\Delta U / \Delta z$ is the change in crosswind with height, and $U\left(Z_{I}\right)$ is the crosswind speed at the generation height]

\begin{tabular}{|c|c|c|c|c|c|c|c|c|c|}
\hline \multirow[b]{2}{*}{$\begin{array}{c}\text { IDF } \\
\text { Run \# } \\
\& \text { date }\end{array}$} & \multirow[b]{2}{*}{$\begin{array}{l}\text { Aircraft } \\
\& \text { Con- } \\
\text { figuration }\end{array}$} & \multirow[b]{2}{*}{$\begin{array}{c}\text { Meteor- } \\
\text { ological } \\
\text { Conditions }\end{array}$} & \multicolumn{3}{|c|}{$\begin{array}{c}\text { Initial Vortex } \\
\text { Parameters }\end{array}$} & \multicolumn{4}{|c|}{ Environmental Parameters } \\
\hline & & & $\begin{array}{c}\Gamma_{\infty} \\
\left(\mathrm{m}^{2} / \mathrm{s}\right)\end{array}$ & $\begin{array}{c}S \\
(\mathrm{~m})\end{array}$ & $\begin{array}{l}Z_{I} \\
(\mathrm{~m})\end{array}$ & $\begin{array}{l}\text { Bulk } \\
\text { Rich- } \\
\text { ardson }\end{array}$ & $\begin{array}{l}\Delta \theta / \Delta z \\
\left({ }^{\circ} \mathrm{C} \text { per }\right. \\
100 \mathrm{~m})\end{array}$ & $\begin{array}{c}\Delta U / \Delta z \\
\left(10^{-2} \mathrm{~s}^{-1}\right)\end{array}$ & $\begin{array}{l}U\left(Z_{I}\right) \\
(\mathrm{m} / \mathrm{s})\end{array}$ \\
\hline $\begin{array}{l}\# 6 \\
9 / 23\end{array}$ & $\begin{array}{l}727-222 \\
\text { landing }\end{array}$ & $\begin{array}{c}\text { stable / } \\
\text { moderate } \\
\text { shear }\end{array}$ & 320 & 26 & 79 & 1 & 8.5 & 5.2 & 5.0 \\
\hline $\begin{array}{l}\# 22 \\
9 / 23\end{array}$ & $\begin{array}{l}727-222 \\
\text { landing }\end{array}$ & $\begin{array}{l}\text { near- } \\
\text { neutral / } \\
\text { moderate } \\
\text { shear }\end{array}$ & 300 & 26 & 76 & .04 & .1 & 3.0 & 5.4 \\
\hline $\begin{array}{c}\# 9 \\
9 / 25\end{array}$ & $\begin{array}{l}757-200 \\
\text { landing }\end{array}$ & $\begin{array}{c}\text { stable / } \\
\text { moderate } \\
\text { shear }\end{array}$ & 365 & 30 & 70 & .5 & 3 & 4.5 & 5.8 \\
\hline $\begin{array}{l}\# 30 \\
9 / 25\end{array}$ & $\begin{array}{c}757-200 \\
\text { landing }\end{array}$ & $\begin{array}{l}\text { unstable / } \\
\text { low shear }\end{array}$ & 360 & 30 & 70 & -5.4 & -0.9 & 0.7 & 2.8 \\
\hline $\begin{array}{l}\# 45 \\
9 / 26\end{array}$ & $\begin{array}{c}\text { 757-200 } \\
\text { takeoff }\end{array}$ & $\begin{array}{l}\text { stable / } \\
\text { low shear }\end{array}$ & 355 & 30 & 79 & 1.9 & 5.9 & 3.2 & 2.8 \\
\hline $\begin{array}{c}\# 7 \\
9 / 29\end{array}$ & $\begin{array}{l}767-200 \\
\text { landing }\end{array}$ & $\begin{array}{l}\text { stable / } \\
\text { moderate } \\
\text { shear }\end{array}$ & 375 & 38 & 70 & 0.6 & 7.5 & 6.4 & 4.1 \\
\hline $\begin{array}{l}\# 23 \\
9 / 30\end{array}$ & $\begin{array}{c}767-200 \\
\text { takeoff }\end{array}$ & $\begin{array}{c}\text { stable / } \\
\text { low shear }\end{array}$ & 370 & 38 & 76 & 16 & 5 & 1.0 & 1.7 \\
\hline $\begin{array}{l}\# 31 \\
9 / 30\end{array}$ & $\begin{array}{l}767-200 \\
\text { landing }\end{array}$ & $\begin{array}{l}\text { unstable / } \\
\text { low shear }\end{array}$ & 375 & 38 & 70 & -15 & -0.2 & 0.02 & 2.0 \\
\hline
\end{tabular}

8

American Institute of Aeronautics and Astronautics 

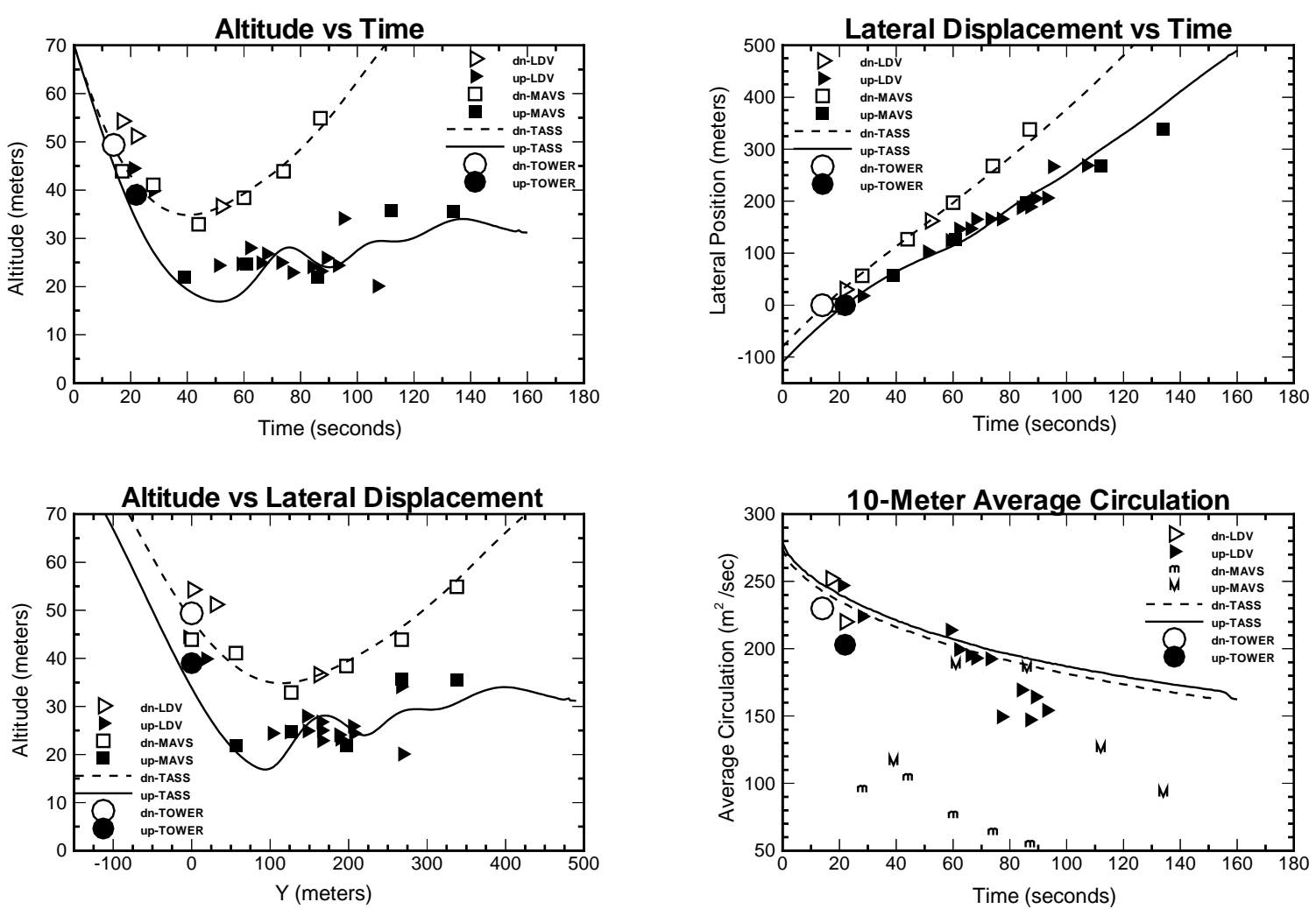

Figure 1. Comparison of TASS results with field data for the Idaho Falls B-757 Run 9 case. The figures (left to right) are: altitude of the vortex track with time, lateral position (relative to tower) vs time, altitude vs lateral position, and $10 \mathrm{~m}$ circulation vs time. Upstream positions indicated by solid lines (simulation) and filled symbols (measurements), downstream positions indicated by dashed lines (simulation) and open symbols (measurements). Right triangles, squares, and circles represent LDV, MAVSS, and tower data, respectively. The average circulation estimates for the upstream and downstream vortex from MAVSS are: M and m, respectively. [Field data courtesy of Volpe National Transportation System.]

9

American Institute of Aeronautics and Astronautics 


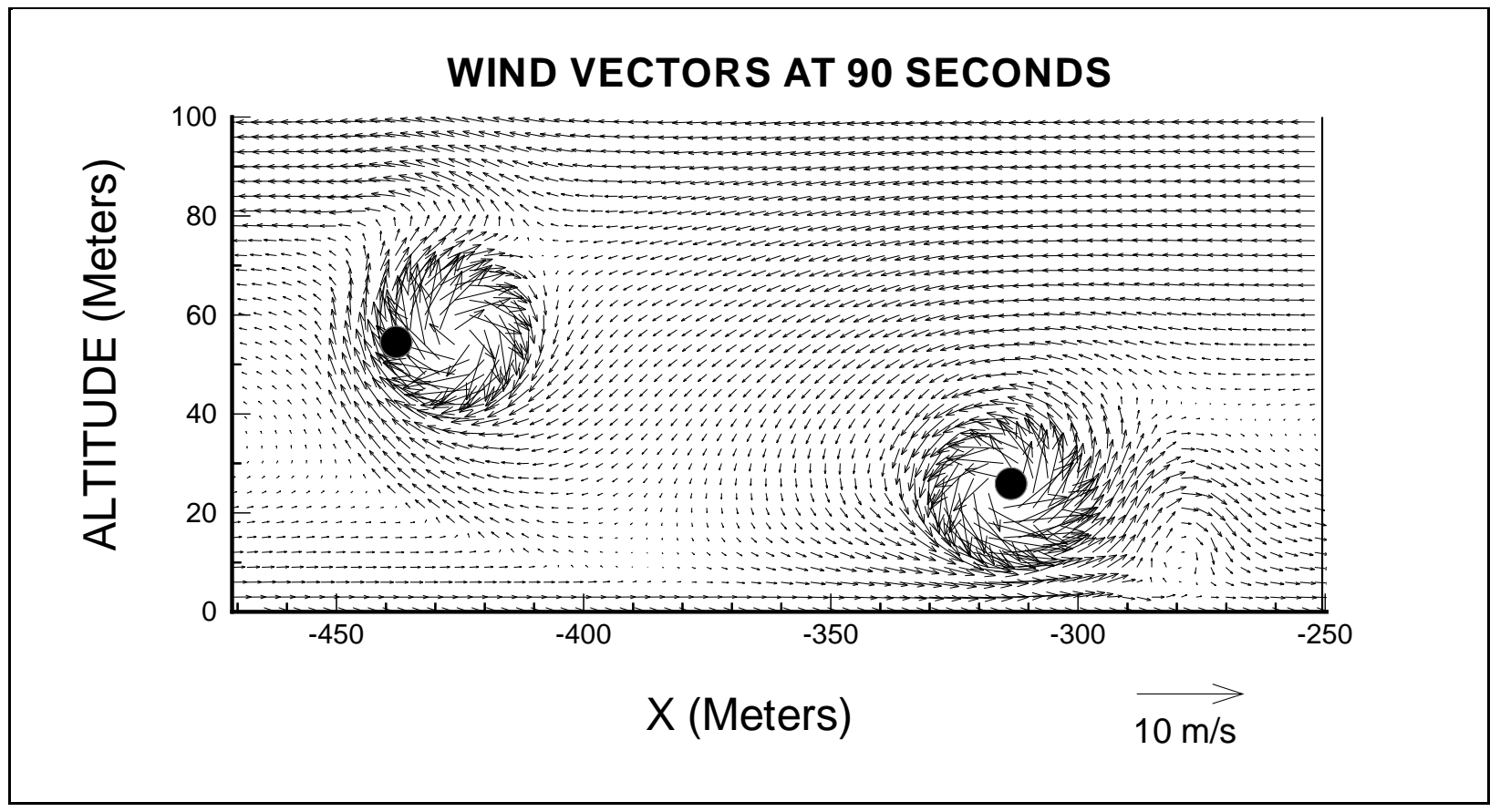

Figure 2. Cross section of simulated wind vector field for IDF B-757 Run 9, at 90 sec after vortex generation. Aircraft track at: $x=0$ and $z=70 \mathrm{~m}$, tower position at: $x=-95 \mathrm{~m}$, both being to the right of the domain. Wind vectors are relative to movement of vortex pair. Observed vortex locations are denoted by filled circles.

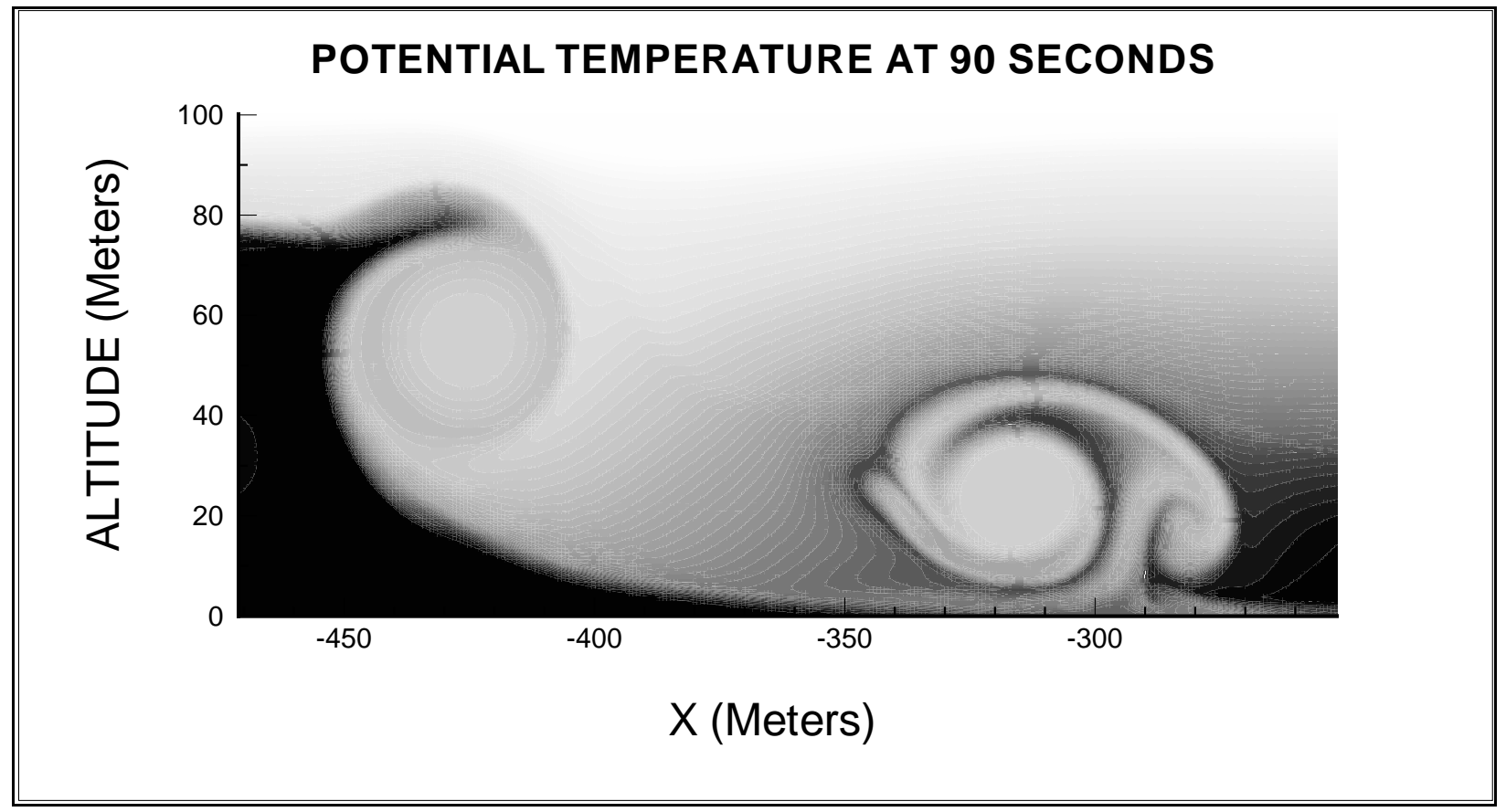

Figure 3. Same as Fig. 2, but for simulated potential temperature. 


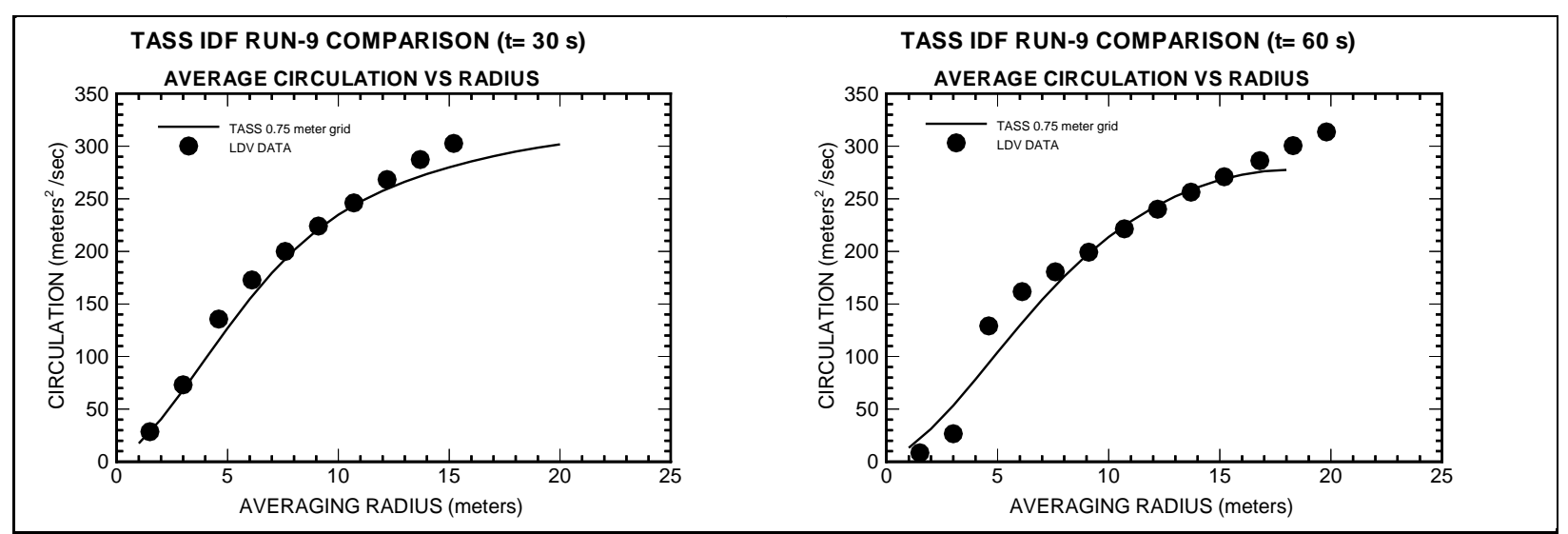

Figure 4. Average circulation vs averaging radius for IDF B-757 Run 9, at $30 \mathrm{sec}$ and $60 \mathrm{sec}$. Simulated data represented by solid line and LDV data by solid circles.

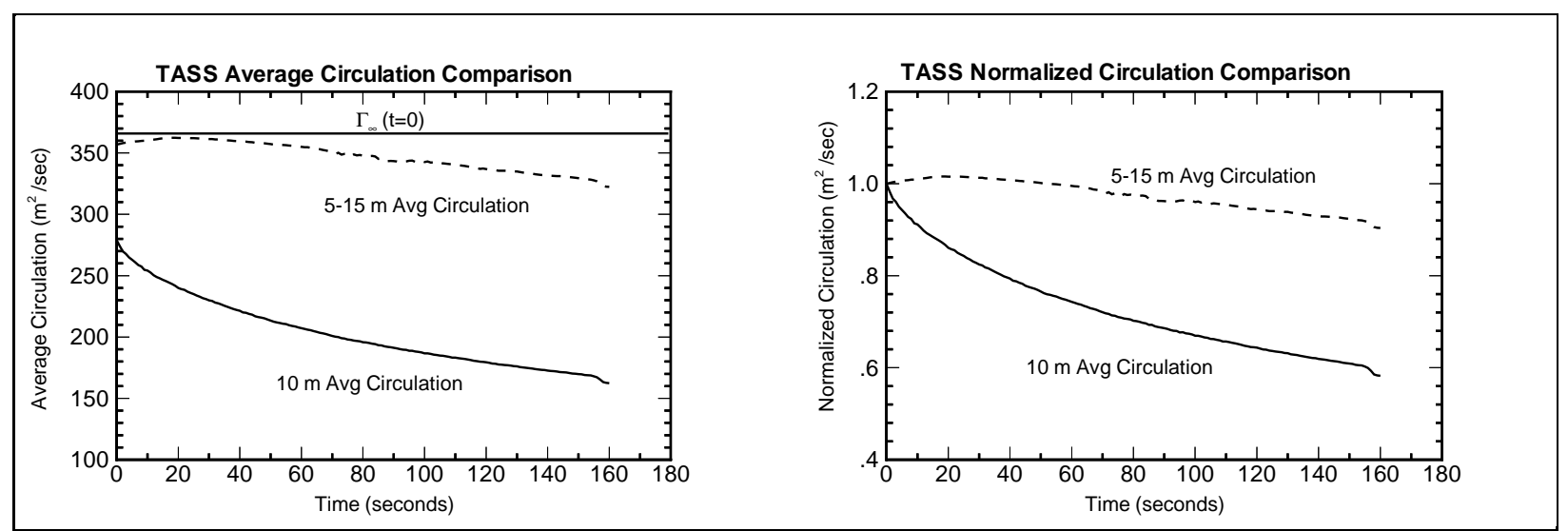

Figure 5. Simulated average circulation vs time for IDF B-757 Run 9. Comparison of $10 \mathrm{~m}$ average circulation and 5-15 $\mathrm{m}$ average circulation. Right figure depicts normalized circulation history.

11 

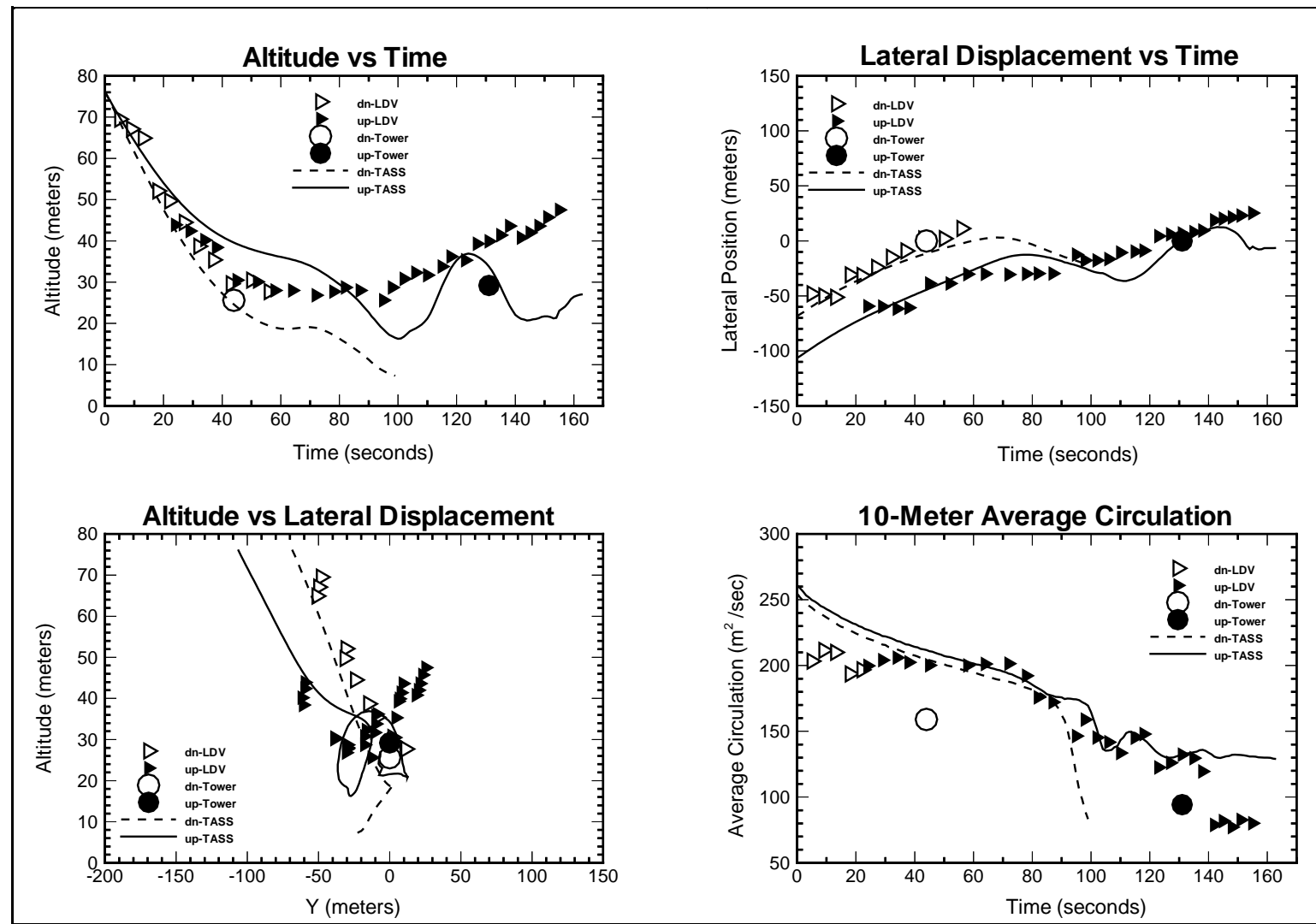

Figure 6. Same as Fig. 1, but for IDF B-767 Run 23.

12 


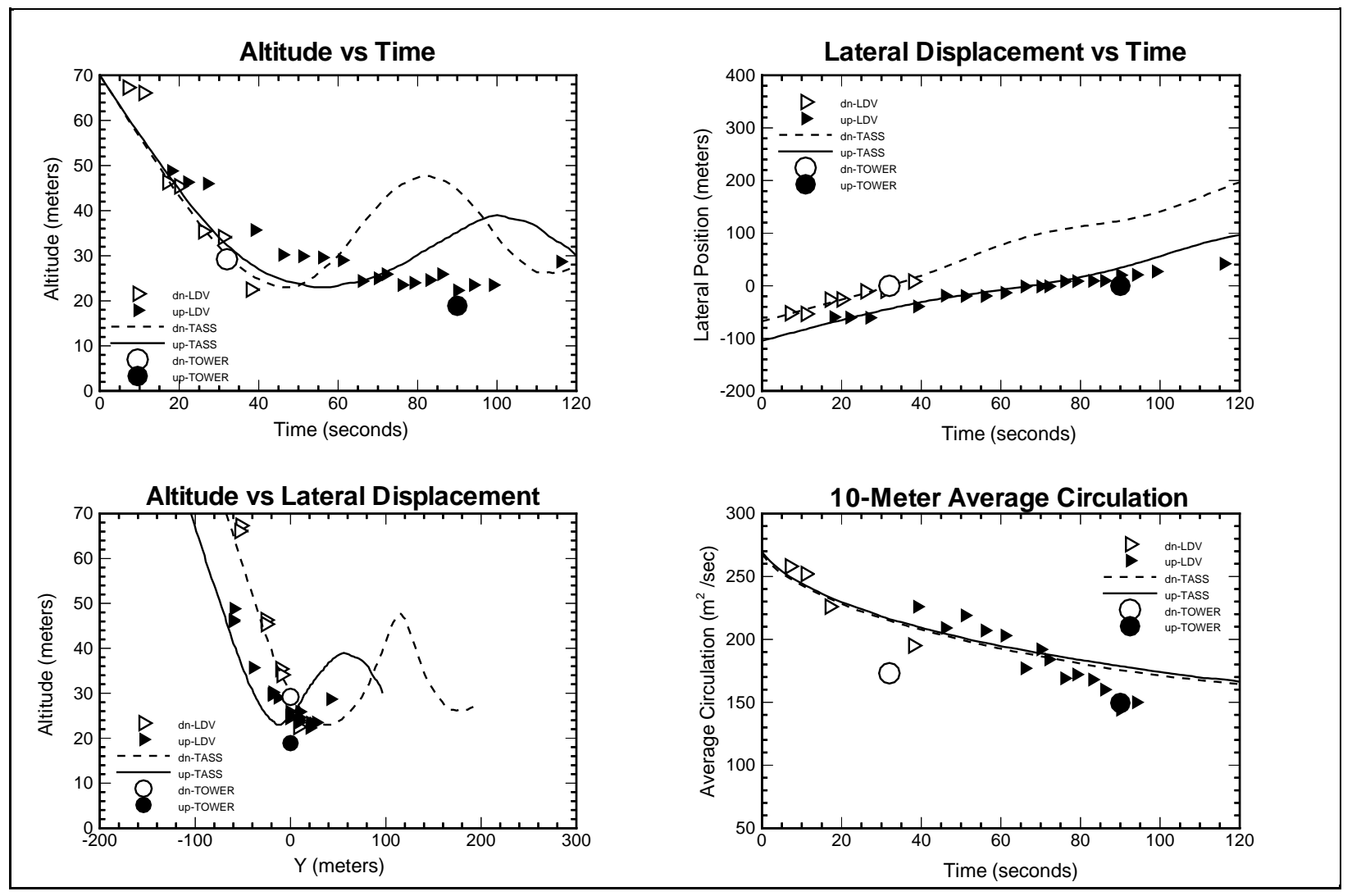

Figure 7. Same as Fig. 1, but for IDF B-767 Run 31.

Table 3. Memphis Validation Cases (symbols as defined in Table 2)

\begin{tabular}{|c|c|c|c|c|c|c|c|c|c|}
\hline \multirow{2}{*}{$\begin{array}{c}\text { MEM } \\
\text { Run \# } \\
\& \\
\text { Aircraft } \\
\text { Type }\end{array}$} & \multirow{2}{*}{$\begin{array}{c}\text { Date \& } \\
\text { Time } \\
\text { (UTC) }\end{array}$} & \multirow{2}{*}{$\begin{array}{l}\text { Meteor- } \\
\text { ological } \\
\text { Conditions }\end{array}$} & \multicolumn{3}{|c|}{$\begin{array}{c}\text { Initial Vortex } \\
\text { Parameters }\end{array}$} & \multicolumn{4}{|c|}{ Environmental Parameters } \\
\hline & & & $\begin{array}{c}\Gamma_{\infty} \\
\left(\mathrm{m}^{2} / \mathrm{s}\right)\end{array}$ & $\begin{array}{c}S \\
(\mathrm{~m})\end{array}$ & $\begin{array}{c}Z_{I} \\
(\mathrm{~m})\end{array}$ & $\begin{array}{l}\text { Bulk } \\
\text { Rich- } \\
\text { ardson }\end{array}$ & $\begin{array}{c}\Delta \theta / \Delta z \\
\left({ }^{\circ} \mathrm{C} \text { per }\right. \\
100 \mathrm{~m})\end{array}$ & $\begin{array}{c}\Delta U / \Delta z \\
\left(10^{-2} \mathrm{~s}^{-1}\right)\end{array}$ & $\begin{array}{l}U\left(Z_{I}\right) \\
(\mathrm{m} / \mathrm{s})\end{array}$ \\
\hline $\begin{array}{l}\# 560 \\
\text { DC-9 }\end{array}$ & $\begin{array}{c}12 / 14 / 94 \\
0113\end{array}$ & $\begin{array}{l}\text { unstable/ } \\
\text { weak shear }\end{array}$ & 215 & 23 & 156 & -800 & -0.1 & $\sim 0$ & 1.9 \\
\hline $\begin{array}{l}\# 586 \\
\text { DC-10 }\end{array}$ & $\begin{array}{c}12 / 14 / 94 \\
0630\end{array}$ & $\begin{array}{l}\text { stable/ } \\
\text { low shear }\end{array}$ & 480 & 37 & 178 & 0.8 & 0.7 & 1.6 & 4.4 \\
\hline $\begin{array}{l}\# 1254 \\
\text { B-727 }\end{array}$ & $\begin{array}{c}8 / 16 / 95 \\
0319\end{array}$ & $\begin{array}{l}\text { stable/ weak } \\
\text { crosswind }\end{array}$ & 245 & 26 & 178 & 17 & 2 & 0.6 & 0.5 \\
\hline $\begin{array}{l}\# 1475 \\
\text { MD-11 }\end{array}$ & $\begin{array}{c}8 / 25 / 95 \\
0344\end{array}$ & $\begin{array}{c}\text { stable/ } \\
\text { weak shear }\end{array}$ & 560 & 41 & 17.5 & 1.6 & 2 & 2 & 1.2 \\
\hline
\end{tabular}

13

American Institute of Aeronautics and Astronautics 

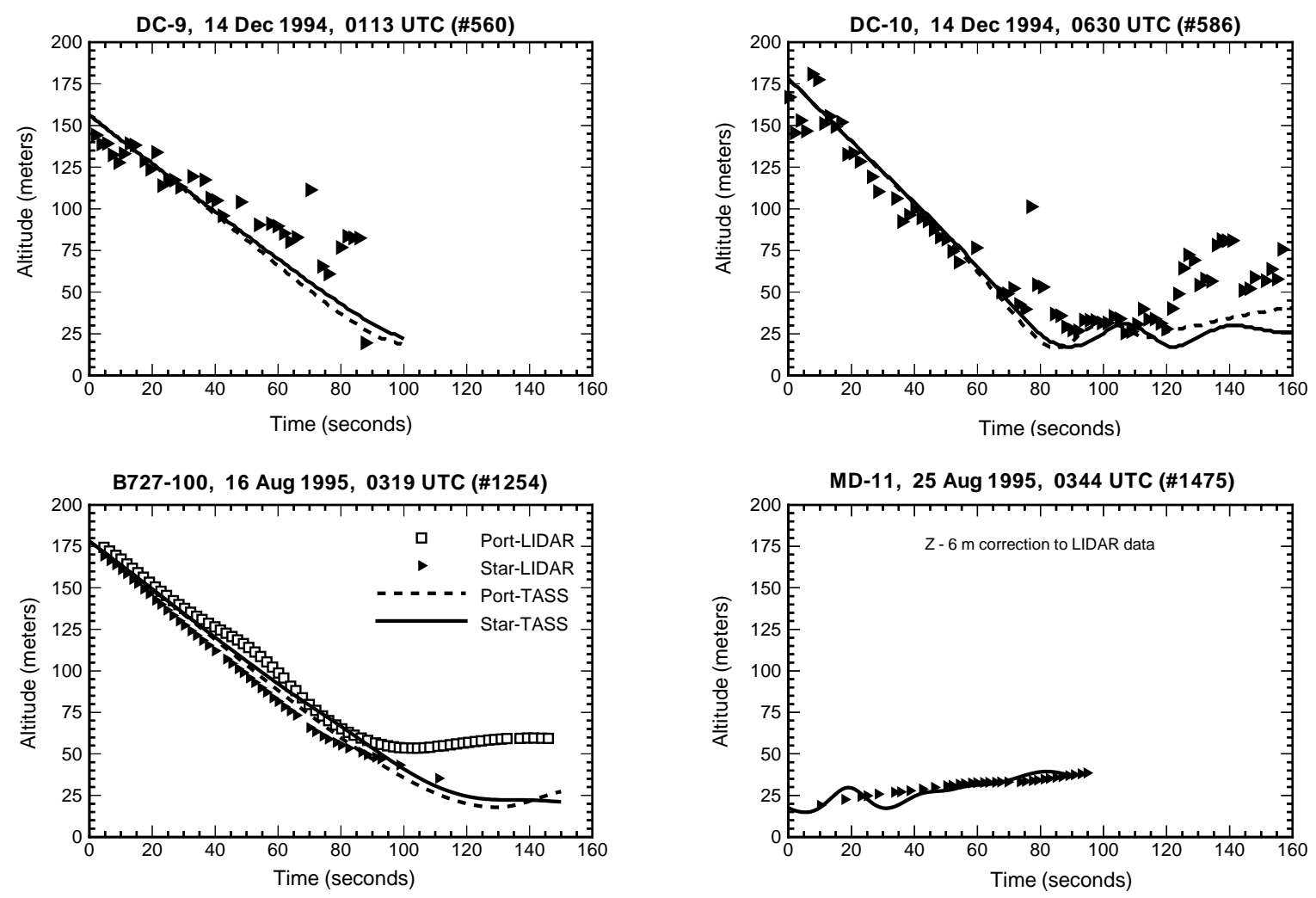

Figure 8. Comparison of TASS results with field data for the four Memphis cases. The figures are altitude of the vortex track vs time with simulated starboard and port portions indicated by solid and dashed lines, respectively. Right triangles and squares represent starboard and port lidar measurements, respectively.

14

American Institute of Aeronautics and Astronautics 

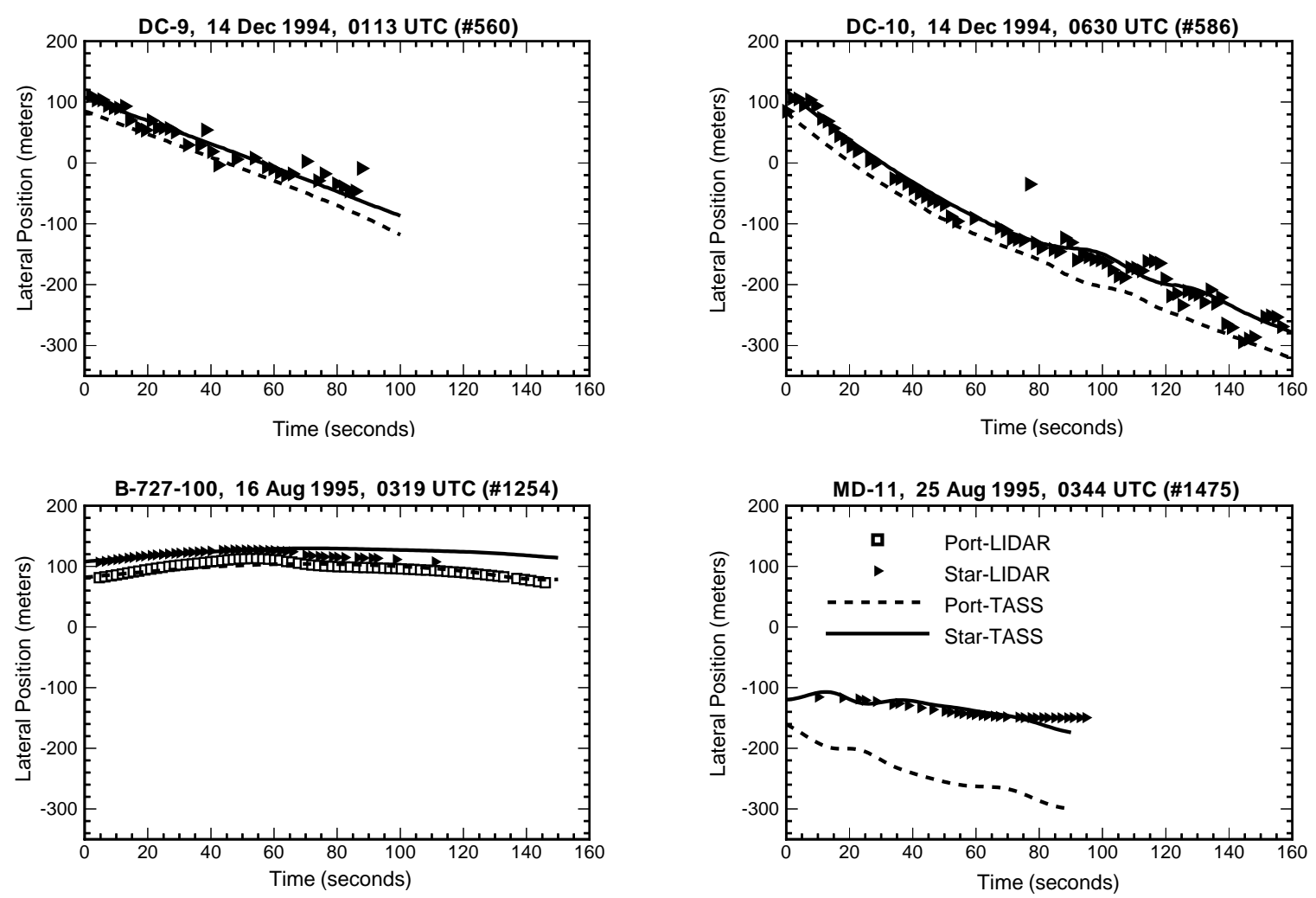

Figure 9. Same as Fig. 8, but for lateral position of the vortex track vs time.

Table A-1. TASS 6.x Numerics

\begin{tabular}{|c|c|c|}
\hline Prognostic Variable & Time Derivative & Space Derivatives \\
\hline $\begin{array}{l}\text { Momentum and } \\
\text { Pressure }\end{array}$ & $\begin{array}{l}\text { Time-split }{ }^{30} \text {-- small time step } \\
\text { for acoustic terms, } \\
\text { 2nd-order Adams-Bashforth: } \\
\text { both large and small time steps }\end{array}$ & $\begin{array}{l}\text { Centered, Quadratic-Conservative Dif- } \\
\text { ferences -- with 4th Order Accuracy for } \\
\text { Convective terms, remaining terms } \\
\text { 2nd Order Accuracy }\end{array}$ \\
\hline $\begin{array}{l}\text { Potential Temperature, } \\
\text { Water Substance, etc. }\end{array}$ & \multicolumn{2}{|c|}{ Third-Order time/space with Upstream-Biased Quadratic Interpolation ${ }^{31}$} \\
\hline
\end{tabular}

\section{Appendix}

\section{TASS Numerics}

Factors that influence the choice of numerical schemes should be: accuracy, economy, and long-term stability; truncation error should not allow the artificial accumulation (or dissipation) of mass, momentum, vorticity, and potential and kinetic energy. Numerical dissipation and/or moderate applications of explicit filtering should be avoided in computational simulations of wake vortex phenomenon, since it may result in the artificial dilation of the vortex core and in exaggerated vortex decay rates. The time-derivative approximations in TASS (see Table A-1) are explicit (for computational efficiency) with minimal numerical dissipation. The 
spatial schemes in TASS are -- Quadratic Conservative Schemes $^{32}$-- which obey certain integral constraints on quadratic quantities, such as kinetic energy. The convective derivatives in the equation of motion are approximated on an Arakawa C-grid ${ }^{33}$ (staggered in space) with 4th-order centered finite differences as formulated by Wilhelmson and $\mathrm{Chen}^{34}$. notation as

Using standard finite difference operator

$$
\begin{gathered}
\delta_{n x} Q\left(x_{i}\right) \equiv \frac{1}{n \Delta x}\left[Q\left(x_{i}+\frac{n \Delta x}{2}\right)-Q\left(x_{i}-\frac{n \Delta x}{2}\right)\right] \\
{\overline{Q\left(x_{i}\right)}}^{n \Delta x} \equiv \frac{1}{2}\left[Q\left(x_{i}+\frac{n \Delta x}{2}\right)+Q\left(x_{i}-\frac{n \Delta x}{2}\right)\right]
\end{gathered}
$$

the finite difference form for the flux component for the $u$ velocity is:

$$
\begin{gathered}
(u u)_{x}+(v u)_{y}+(w u)_{z} \simeq \frac{10}{8} \delta_{x}\left(\bar{u}^{x} \bar{u}^{x}\right) \\
-\frac{1}{8} \delta_{x}\left(\bar{u}^{3 x} \bar{u}^{3 x}\right)-\frac{1}{8} \delta_{3 x}\left(\bar{u}^{x} \bar{u}^{x}\right)+\frac{10}{8} \delta_{y}\left(\bar{v}^{x} \bar{u}^{y}\right) \\
-\frac{1}{8} \delta_{y}\left(\bar{v}^{x} \bar{u}^{3 y}\right)-\frac{1}{8} \delta_{3 y}\left(\bar{v}^{3 x} \bar{u}^{y}\right)+\frac{10}{8} \delta_{z}\left(\bar{w}^{x} \bar{u}^{z}\right) \\
-\frac{1}{8} \delta_{z}\left(\bar{w}^{x} \bar{u}^{3 z}\right)-\frac{1}{8} \delta_{3 z}\left(\bar{w}^{3 x} \bar{u}^{z}\right)
\end{gathered}
$$

Similarly, the finite difference form for the flux component for the $v$ velocity is:

$$
\begin{gathered}
(u v)_{x}+(v v)_{y}+(w v)_{z} \simeq \frac{10}{8} \delta_{x}\left(\bar{u}^{y} \bar{v}^{x}\right) \\
-\frac{1}{8} \delta_{x}\left(\bar{u}^{y} \bar{v}^{3 x}\right)-\frac{1}{8} \delta_{3 x}\left(\bar{u}^{3 y} \bar{v}^{x}\right)+\frac{10}{8} \delta_{y}\left(\bar{v}^{y} \bar{v}^{y}\right) \\
-\frac{1}{8} \delta_{y}\left(\bar{v}^{3 y} \bar{v}^{3 y}\right)-\frac{1}{8} \delta_{3 y}\left(\bar{v}^{y} \bar{v}^{y}\right)+\frac{10}{8} \delta_{z}\left(\bar{w}^{y} \bar{v}^{z}\right) \\
-\frac{1}{8} \delta_{z}\left(\bar{w}^{y} \bar{v}^{3 z}\right)-\frac{1}{8} \delta_{3 z}\left(\bar{w}^{3 y} \bar{v}^{z}\right)
\end{gathered}
$$

and the finite difference form for the flux component for the $w$ velocity is:

$$
\begin{gathered}
(u w)_{x}+(v w)_{y}+(w w)_{z} \approx \frac{10}{8} \delta_{x}\left(\bar{u}^{z} \bar{w}^{x}\right) \\
-\frac{1}{8} \delta_{x}\left(\bar{u}^{z} \bar{w}^{3 x}\right)-\frac{1}{8} \delta_{3 x}\left(\bar{u}^{3 z} \bar{w}^{x}\right)+\frac{10}{8} \delta_{y}\left(\bar{v}^{z} \bar{w}^{y}\right) \\
-\frac{1}{8} \delta_{y}\left(\bar{v}^{z} \bar{w}^{3 y}\right)-\frac{1}{8} \delta_{3 y}\left(\bar{v}^{3 z} \bar{w}^{y}\right)+\frac{10}{8} \delta_{z}\left(\bar{w}^{z} \bar{w}^{z}\right) \\
-\frac{1}{8} \delta_{z}\left(\bar{w}^{3 z} \bar{w}^{3 z}\right)-\frac{1}{8} \delta_{3 z}\left(\bar{w}^{z} \bar{w}^{z}\right)
\end{gathered}
$$

The divergence term in the $u$-equation of motion in finite difference form is:

$$
\begin{gathered}
u\left[u_{x}+v_{y}+w_{z}\right] \simeq u\left[\frac{9}{8}\left(\delta_{x} u+\delta_{y} v+\delta_{z} w\right)\right. \\
\left.-\frac{1}{8}\left(\delta_{3 x} u+\delta_{3 y} v+\delta_{3 z} w\right)\right]
\end{gathered}
$$

and similarly for $v$ an $w$. 


\section{References}

1. Hinton, D.A., "Aircraft Vortex Spacing System (AVOSS) Conceptual Design," NASA Tech Memo \# 110184, August 1995, 27 pp.

2. Proctor, F.H., "The Terminal Area Simulation System. Volume I: Theoretical Formulation," NASA Contractor Rep. 4046, NASA, Washington, DC, April 1987, 176 pp. [Available from NTIS \}

3. Bilanin, A.J., Teske, E.M., and Hirsh, J.E., "Neutral Atmospheric Effects on the Dissipation of Aircraft Vortex Wakes," AIAA Journal, Vol. 16, No. 9, 1978, pp. 956-951.

4. Robins, R.E. and Delisi, D.P., "Numerical Study of Vertical Shear and Stratification Effects on the Evolution of a Vortex Pair," AIAA Journal, Vol 28, No. 4, 1990, pp. 661-669.

5. Schilling, V.K., "Motion and Decay of Trailing Vortices within the Atmospheric Surface Layer," Beitr. Phys. Atmosph., Vol 65, No. 2, 1992, pp. 157-169.

6. Robins, R.E. and Delisi, D.P., "Potential Hazard of Aircraft Wake Vortices in Ground Effect with Crosswind," J. Aircraft, Vol. 30, No. 2, 1993, pp. 201-206.

7. Teske, M.E., Bilanin, A.J., and Barry, J.W., "Decay of Aircraft Vortices Near the Ground," AIAA Journal, Vol. 31, No. 8, 1993, pp. 1531-1533.

8. Zheng, Z.C, and Ash, R.L, "Study of Aircraft Wake Vortex Behavior Near the Ground," AIAA Journal, Vol. 34, No. 3, 1996, pp. 580-589.

9. Proctor, F.H., "The Terminal Area Simulation System. Volume II: Verification Experiments," NASA Contractor Rep. 4047, NASA, Washington, DC, April 1987, 112 pp. [Available from NTIS]

10. Proctor, F.H., "Numerical Simulations of an Isolated Microburst. Part I: Dynamics and Structure," J. Atmos. Sci., Vol. 45, No. 21, 1988, pp. 3137-3160.

11. Proctor, F.H., "Numerical Simulations of an Isolated Microburst. Part II: Sensitivity Experiments," J. Atmos. Sci., Vol. 46, No. 14, 1989, pp. 2143-2165.
12. Proctor, F.H., and Bowles, R.L., "Three-

Dimensional Simulation of the Denver 11 July 1988 Microburst-Producing Storm," Meteorol. and Atmos. Phys., Vol. 49, 1992, pp. 107-124.

13. Proctor, F.H., Bracalente, E.M., Harrah S.D. , Switzer, G.F., and Britt, C.L., " Simulation of the 1994 Charlotte Microburst with Look-Ahead Windshear Radar," Preprints, 27th Conference on Radar Meteorology, Vail, CO, Amer. Meteor. Soc., Oct. 1995, pp. 530-532.

14. Proctor, F.H., "Three-Dimensional Simulation of the 2 August CCOPE Hailstorm with the Terminal Area Simulation System," Report of the International Cloud Modelling Workshop/Conference, Irsee FRG, WMO Tech. Document No. 139, Sept. 1986, pp. $227-$ 240.

15. Kulie, M.S., Lin, Y-L, Deal, R.L, DeCroix, D.S, "A Cloud-Scale Numerical Simulation of the 28 November 1988 Raleigh Tornadic Thunderstorm," Preprints, 18th Conference on Severe Local Storms, San Francisco, CA, Amer. Meteor. Soc., Feb. 1996, pp. 283-287.

16. Bacon, D.B., Dunn, J.T., Sands, M.R. and Sarma, R.A., "Single Burst Nuclear Cloud Database, Volume 1 -- Cloud Rise and Stabilization Modeling," DNATR-90-36-V1, June 1991, 151 pp.

17. Schowalter, D.G., DeCroix, D.S., Lin, Y.-L., Proctor, F.H., Arya, S.P., and Kaplan, M.L., "Turbulent Statistics in the Atmospheric Boundary Layer: a Comparison of Large Eddy Simulation with Observations," Preprints, 11th Symposium on Boundary Layers and Turbulence, Charlotte, NC, Amer. Meteor. Soc., March 1995, pp. 552-555.

18. Schowalter, D.G., DeCroix, D.S., Lin, Y.-L., Arya, S.P., and Kaplan, M.L., "Planetary Boundary Layer Simulation Using TASS," NASA Contractor Rep. 198325, April 1996, 22 pp.

19 Proctor, F.H., "A Numerical Study of the Evolution of Tornadoes," $\mathrm{PhD}$ dissertation, Texas A\&M University, College Station, TX, Dec. 1982, 267 pp. [Available from University Microfilms International, Ann Arbor Michigan, No. 83-09-693] 
20. Lilly, D.K., "On the Numerical Simulation of Buoyant Convection," Tellus, Vol. 14, 1962, pp. 148-172.

21. Burnham, D.C. and Hallock, J.N., "Chicago Monostatic Acoustic Vortex Sensing System, Volume IV: Wake Vortex Decay," Department of

Transportation, Rep. No. DOT/FAA/RD-79-103 IV, July 1982, 206 pp. [Available from NTIS]

22. Karamcheti, K., Principles of Ideal-Fluid Aerodynamics, Robert E. Krieger Publishing Co., 1980, pp. 548-550.

23. Garodz, L.J., and Clawson, K.L., "Vortex Wake Characteristics of B757-200 and B767-200 Aircraft Using the Tower Fly-By Technique, Volumes 1 and 2," NOAA Tech. Memo. ERL ARL-199, Jan. 1993. [Available from NTIS]

24. Rudis, R.P., et al, "Data Compilation, Laser Doppler System, Acoustic Doppler System, High Resolution Anemometer," Wake Vortex Research Data Package No. VNTSC/IDF-1, Volpe National Transportation Systems Center, Cambridge, MA, 1990.

25. Systems Research Corporation, "Atmospheric Description for Idaho Falls B-757 Run \#9 on September 25, 1990," Volpe National Transportation Systems, Cambridge, MA, Jan. 1994.

26. Burnham, D.C., Scientific and Engineering Solutions, Inc., personal communication, 1996.

27. Campbell, S.D., Dasey, T., Heinricks, R., and Matthews, M.P., "Overview of 1994 Memphis Wake Vortex Testing Program," Sixth Conf. on Aviation Weather Systems, Dallas TX, Amer. Meteor. Soc., Jan 1995.

28. Campbell, S.D., Dasey, T., Freehart, R., Heinricks, R., Matthews, M.P., and Perras, G., "Wake Vortex Field Measurement Program at Memphis, TN," 34th Aerospace Science Meeting \& Exhibit, Reno, NV, Jan. 1996.

29. Dasey, T.J., and Heinricks, R., "An Algorithm for the Recognition and Tracking of Aircraft Wake Vortices with a Continuous Wave Coherent Laser Radar," Optical Society of American Coherent Laser Radar Topical Meeting, Keystone, CO, July 1995.
30. Klemp, M.L., and Wilhelmson, R.B., "The Simulation of Three-Dimensional Convective Storm Dynamics," J. Atmos. Sci., Vol. 35, 1978, pp. 1070-1096.

31. Leonard, B.P., "A Stable and Accurate Convective Modelling Procedure Based on Quadratic Upstream Interpolation," Comp. Meth. Appl. Mech. Eng., Vol. 19, 1979, pp. 59-98.

32. Arakawa, A., "Computational Design for Long Term Numerical Integration of the Equations of Fluid Motion: Two-Dimensional Incompressible Flow, Part I," J. Comp. Phys., Vol. 1, 1966, pp. 119-143.

33. Haltiner, G.J. and Williams, R.T., Numerical Prediction and Dynamic Meteorology, Second Edition, John Wiley \& Sons, 1980, pp. 226-230.

34. Wilhelmson, R.B. and Chen, C-S, "A Simulation of the Development of Successive Cells Along a Cold Outflow Boundary," J. Atmos. Sci., Vol. 39, 1982, pp. 1466-1483. 